\title{
Visualisation and bibliometric analysis of worldwide research trend of stress among seafarer: an extensive publication analysis
}

\author{
Manik Sharma
}

Department of CSA, DAV University Jalandhar, India

\begin{abstract}
Stress is the most predominant and worldwide psychological human condition that undoubtedly impedes the state of mind of the individuals. During the last few years, a tremendous change and growth in the global publishing trend for human stress have been observed. Like other professionals (doctors, bankers, teachers, and businessmen), the mariners or seafarers are also being the most common victims of this human psychological disorder (stress) these days. The keywords "seafarer" and "stress" have been exposed to mine the research trend of the articles exploring the stress among the seafarers. From 2001 to 2020, more than six thousand (6211) human stress-based articles have been reported in Scopus indexing database. However, the number of articles related to the stress among seafarer is 136 only i.e. 2.18\% of the human-stress based articles. The research related to the psychological disorder (stress) among seafarer has been increased during the last two decades. Germany, United Kingdom and Italy found to be the topmost countries for exploring the stress among the seafarer. The study concluded that the human psychological conditions like bulimia, anorexia nervosa, obsessive-compulsive disorder, schizophrenia, generalised anxiety disorder, cyclothymia, mood, conduct, and personality disorders along with stress still need to be extensively mined to diagnose the state of mind of seafarers.
\end{abstract}

(Int Marit Health 2021; 72, 1: 64-75)

Key words: seafarer, psychological disorders, stress, maritime industry

\section{INTRODUCTION}

The bibliometric and publishing study assists in getting the complete publication and citation trend of the articles [1]. This information will assist in finding the impact and influence of research domain, articles, journals, publishers, authors, research groups and funding agencies. The details regarding universities, authors, research groups and countries who are pursuing their research work in specific areas for the welfare of the society can be easily extracted from a bibliometric analysis. The details of funding agencies that support similar kind of work can also be extracted through the research trend of this study. The ideas relating to stress, related works, and the novelty of this research work have been briefly highlighted in the rest of this section.

\section{STRESS}

Earlier, cancer, diabetes and heart attacks were the most critical and prevalent global human disorders [2]. However, nowadays, the psychiatric disorders are the most proliferating human diseases. Stress is a predominant, persistent and global human psychiatric disorder. It is a human psychiatric disorder that inevitably revamps the state-of-mind of an individual [3, 4]. It affects the thinking, moving, walking, eating and working capacity of the victim. The late diagnosis of stress may intricate several other human critical disorders like diabetes, stroke, anxiety and depression. Therefore, it is intended to diagnose these psychiatric conditions at an early stage.

Manik Sharma, PhD, Department of CSA, DAV University Jalandhar, India, e-mail: manik_sharma25@yahoo.com 


\section{RELATED WORKS}

Earlier, different studies have been carried out to explore the publishing and bibliometric trend for disaster health [5], public health research [6], open-access [7], clinical radiology [8], predatory journals [9], epidemiology [10], health services [11], ergonomics [12], feature selection [13], and neurological disorders [14]. However, a little attention is given to mine the research trend of stress among maritime industry workers. The maritime industry is the backbone of the world trade business and is responsible for globalization and foreign exchange.

\section{NOVELTY}

The objective of this study is to examine and highlight the publishing trend of stress among seafarer based articles. A Scopus indexing database has been explored for the same. The period of observation was restricted to two decades i.e. 2001 to 2020. Here, an extensive research trend analysis in terms of global publications, sources (books, journals, and conferences), countries, access (open/closed), and languages have been explored. The list of productive journals, universities, and funding agencies active in this research area has also been highlighted.

The methodology used in this bibliometric analysis is presented in section "Materials and methods". The results and discussions are summarised in section "Results and discussion". Finally, the work is concluded in section "Concluding remarks and future directions".

\section{DATA SOURCES \\ MATERIALS AND METHODS}

The Scopus indexing database has been mined for this bibliometric analysis. The articles related to the human-stress and stress among seafarers published between 2001 and 2020 were extracted and explored.

\section{SEARCH STRATEGY}

In Scopus, the search term "(TITLE-ABS-KEY ("seafarer" AND "stress") AND (LIMIT-TO (PUBYEAR,2020) OR LIMIT-TO (PUBYEAR,2019) OR LIMIT-TO (PUBYEAR,2018) OR LIMIT-TO (PUBYEAR,2017) OR LIMIT-TO (PUBYEAR,2016) OR LIMIT-TO (PUBYEAR,2015) OR LIMIT-TO (PUBYEAR,2014) OR LIMIT-TO (PUBYEAR,2013) OR LIMIT-TO (PUBYEAR,2012) OR LIMIT-TO (PUBYEAR,2011) OR LIMIT-TO (PUBYEAR,2010) OR LIMIT-TO (PUBYEAR,2009) OR LIMIT-TO (PUBYEAR,2008) OR LIMIT-TO (PUBYEAR,2007) OR LIMIT-TO (PUBYEAR,2006) OR LIMIT-TO (PUBYEAR,2005) OR LIMIT-TO (PUBYEAR,2004) OR LIMIT-TO (PUBYEAR,2003) OR LIMIT-TO (PUBYEAR,2002) OR LIMIT-TO (PUBYEAR,2001) )" has been mined for analysis of this study. Both subscription and open-access based articles, conference papers, reviews, book chapters, letters, notes, editorials, and books have been considered for this investigation.
The data extracted from Scopus have been mined for the countries, research categories, universities, and languages.

Moreover, the publication trend for some major psychiatric conditions like bulimia, anorexia nervosa, obsessive-compulsive disorder, schizophrenia, generalised anxiety disorder, cyclothymia, mood, conduct, and personality disorders have also been assessed. This research trend analysis assists to gain clear insights regarding the variation in publication trend of stress and other human psychiatric conditions.

\section{RESULTS AND DISCUSSION STRESS AMONG SEAFARER RELATED ARTICLES IN THE WORLD}

The number of the last 20 years worldwide publications relevant to the keywords used in the search strategy has been depicted in Figure 1A. In the last two decades, the number of publications per year has increased from 1 to 18 nearly. Moreover, thirty seven different countries have carried out research related to this theme. The country-wise publishing details are presented in Figure 1B. The highest number of publications are from Germany (24), followed by the United Kingdom (20) and Italy (11).

The source-wise distribution (Fig. $1 \mathrm{C}$ ) reflects that the studies related to the theme under observation have been published in the form of research articles, notes, letters, book chapters, reviews, conference papers, books, and editorials. More editorials and short communications are required to cover the publication gaps for these studies. The contribution of subscription (63\%) and open-access (37\%) based articles are reported in Figure 1D. Despite English, some of the studies have also been authored in German, French, Chinese, Italians and Croatian (Fig. 1E).

\section{STATISTICS}

In the previous 10 years (2011-2020), the number of worldwide publications related to seafarer stress has skyrocketed from 1 to 136 . A positive growth trend $\left(R^{2}=0.693308\right)$ has been observed. The statistics report for the same is depicted in Table 1 . The coefficient of determination $\left(\mathrm{R}^{2}\right)$ indicates that $70 \%$ (approx.) of variation of several publications around the mean are completely extracted by the year of publication that means $70 \%$ of values fit the regression model.

\section{RESEARCH CATEGORIES}

Globally, 19 distinct research categories (Agricultural, Biological Sciences, Arts, Humanities, Decision Science, Computer Science, Chemical Engineering etc.) related to stress among seafarers have been found (Fig. 2). Among these distinct categories, medicine $(83,61.02 \%)$ social sciences (34, 25\%), engineering $(31,22.79 \%)$, and environmental sciences $(19,13.97 \%)$ found to be more common. 


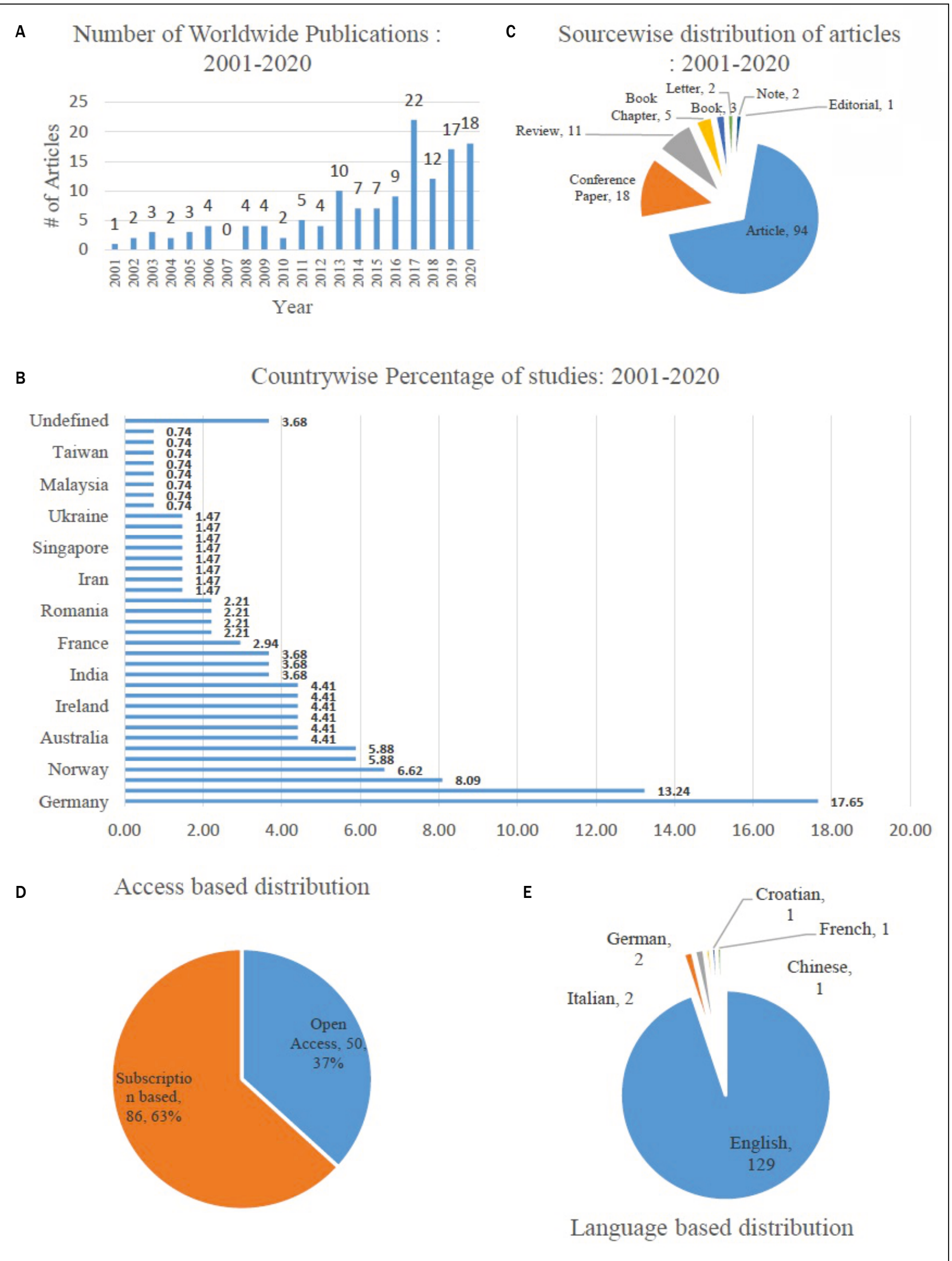

Figure 1. Stress among seafarer related articles; A. Number of Worldwide Publications: 2001-2020; B. Countrywise Percentage of studies: 2001-2020; C. Distribution of articles: 2001-2020; D. Access based distribution; E. Language-based distribution. 
However, the categories like computer science, decision science, energy need to be more explored as far the stress among seafarer is concerned. A significant variation of these publication categories has been found. More conferences and symposiums related to the theme are intended to be arranged to disseminate knowledge among young professionals and to motivate them for future research works.

\section{CONTRIBUTION OF UNIVERSITY}

Several authors from distinct global universities are working on mining and management of stress among the seafarer. The names of the universities along with the number of articles published in the area of stress among seafarers are presented in Table 2. The Universitätsklinikum Hamburg-Eppendorf und Medizinische found to be a leader for such kind of publications.

Table 1. Statistics

\begin{tabular}{ll}
\hline Regression statistics & \\
\hline Multiple R & 0.832314 \\
R square & 0.692747 \\
Adjusted R square & 0.675677 \\
Standard error & 3.494022 \\
Observations & 20
\end{tabular}

Table 2. Universities contribution

\begin{tabular}{ll}
\hline University & $\begin{array}{l}\text { Article } \\
\text { published }\end{array}$ \\
\hline Universitätsklinikum Hamburg-Eppendorf & 20 \\
und Medizinische Fakultät & \\
University of Southern Denmark, Esbjerg & 8 \\
Cardiff University & 8 \\
Gdanski Uniwersytet Medyczny & 7 \\
Università degli Studi di Camerino & 7 \\
Australian Maritime College & 5 \\
Universität Hamburg & 5 \\
Stellenbosch University & 4 \\
Akademickie Centrum Medycyny Morskiej & 4 \\
i Tropikalnej & \\
Trinity College Dublin & 4 \\
University of Tasmania & 4 \\
University of Zadar & 4 \\
Fachhochschule Münster - Abteilung Steinfurt & 4 \\
AMET University & 3 \\
Univerzita Palackého v Olomouci & 3 \\
Kobe University & 3 \\
Memorial University of Newfoundland & 3 \\
Maynooth University & 3 \\
Dalian Maritime University & 3 \\
Centre for Risk, Integrity and Safety Engineering & 3 \\
& \\
\hline
\end{tabular}

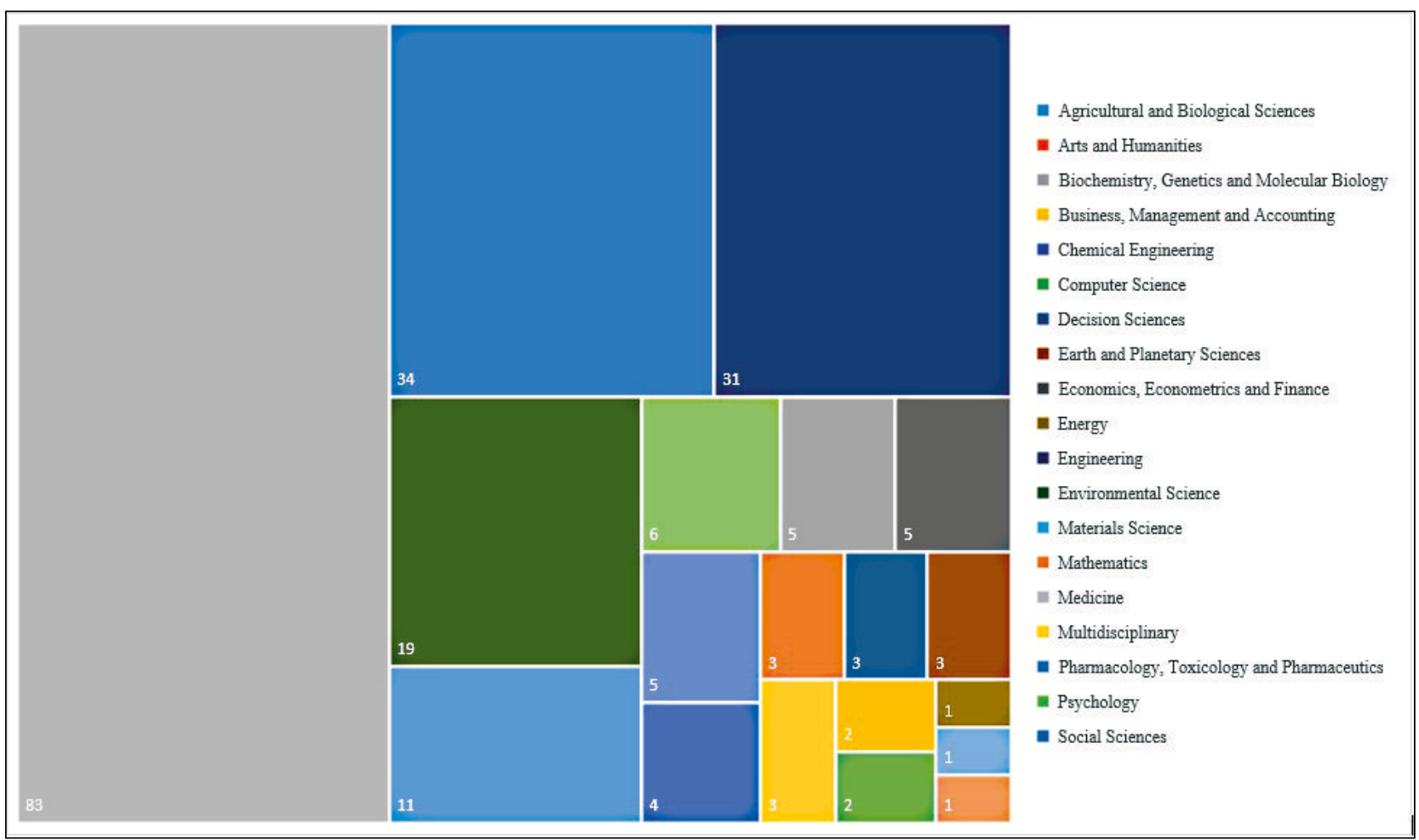

Figure 2. Research categories for stress among the seafarer 


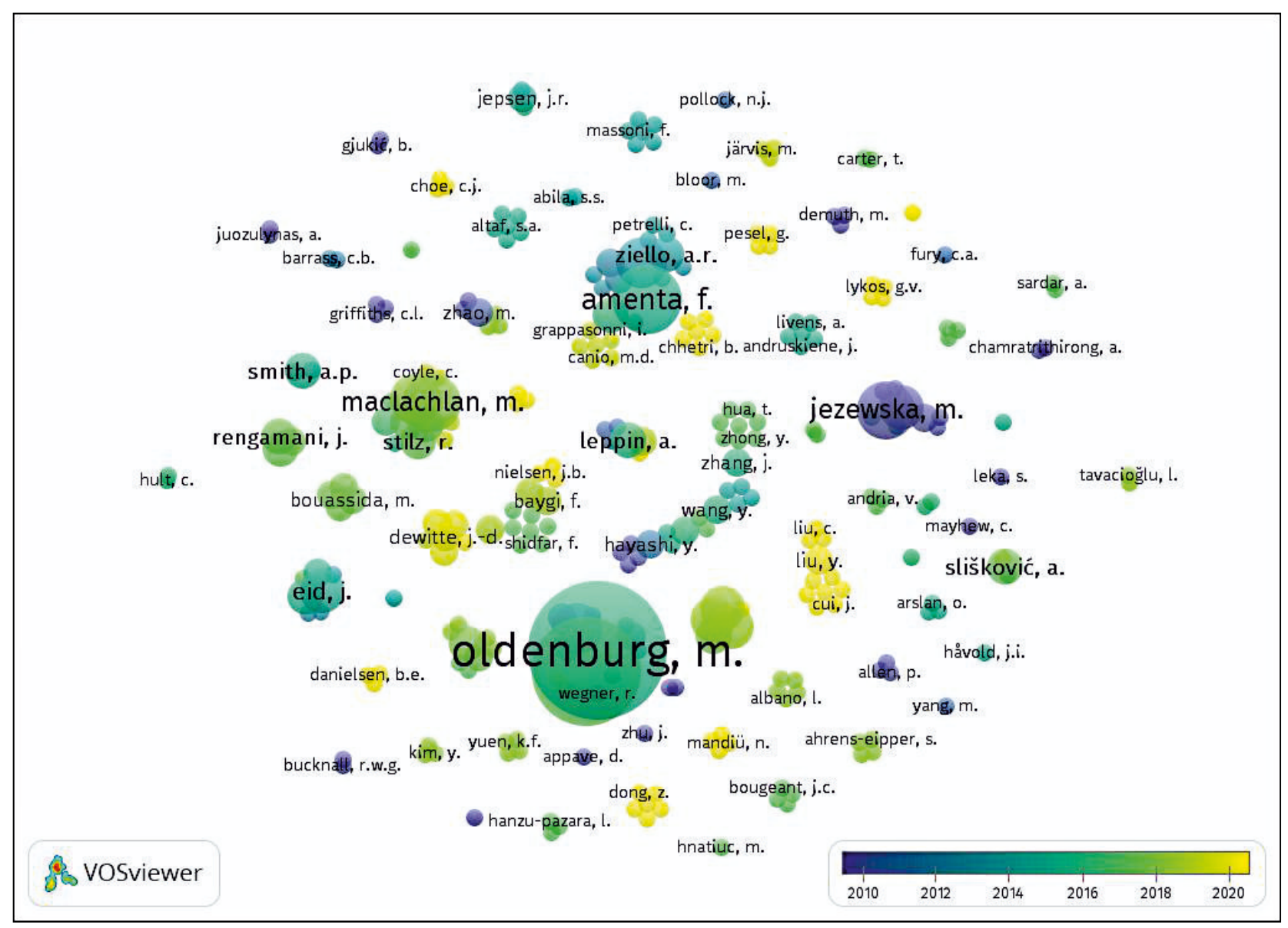

Figure 3. Authors' network map

\section{AUTHORS' NETWORK}

Several researchers are working in the area of mining and management of stress among mariners. The collaboration of the authors has been presented in Figure 3. This map assists in finding the collaboration network of the authors. This information will be useful for naïve researchers who want to do collaborative research in this domain. The authors map indicates that a total link strength of twenty and greater is observed for six different authors. The highest number of publications (23) has been recorded for the M. Oldenburg.

Table 3 depicts the country-wise international collaboration in mining and management of stress among seafarers. The link strength signifies the rate of international collaboration. The highest level of international collaboration has been asserted for the United Kingdom, followed by Ireland and the United States.

\section{KEYWORDS FREQUENCY}

A list of high-frequency keywords (found in the explored publications) has been extracted in the form of triplet i.e. (Keyword, Frequency, Total-Link Strength). The (human, 79,
1062), (ships, 55, 682), (male, 45, 722), (adult, 41, 686), (medicine, 39, 555), (mental-stress, 36,559), (stress, 30, 492), (occupational-health, 28,426), (psychology, 24,386), (occupational-disease, 18, 286), and (mental-health, 15, 196) are some of the instances of the triplets. The keyword distribution map for the same is presented in Figure 4.

\section{JOURNAL AND FUNDING CONTRIBUTION}

As per the search strategy, a total of 136 articles have been filtered out that recognise the use of two important keywords viz. stress and seafarer. Out of 136 articles, 94 have been published in different journals. The bifurcation publishing details are shown in Table 4. As per the search strategy (mentioned in section "Search strategy"), the International Maritime Health found to be a top contributed journal. The results witnessed that $30.85 \%$ of the articles have been published in this journal alone.

A network map for citations (organisations) has also been created (Fig. 5). The organisation having cumulative citations of less than ten has been excluded from this analysis. Globally, 59 different organisations have met this criterion. As far as organisational citations are considered 
Table 3. International collaboration

\begin{tabular}{|c|c|c|}
\hline Country & Documents & Total link strength \\
\hline Germany & 24 & 0 \\
\hline United Kingdom & 18 & 13 \\
\hline Italy & 11 & 5 \\
\hline Denmark & 9 & 6 \\
\hline Norway & 9 & 1 \\
\hline China & 8 & 5 \\
\hline Australia & 6 & 4 \\
\hline Canada & 6 & 4 \\
\hline Croatia & 6 & 0 \\
\hline Ireland & 6 & 10 \\
\hline Poland & 7 & 0 \\
\hline United States & 6 & 9 \\
\hline India & 5 & 4 \\
\hline South Africa & 5 & 9 \\
\hline South Korea & 5 & 3 \\
\hline France & 4 & 3 \\
\hline Czech Republic & 3 & 7 \\
\hline Japan & 3 & 1 \\
\hline Romania & 3 & 0 \\
\hline Sweden & 3 & 0 \\
\hline Greece & 2 & 1 \\
\hline Iran & 2 & 3 \\
\hline Lithuania & 2 & 0 \\
\hline Philippines & 2 & 4 \\
\hline Singapore & 2 & 1 \\
\hline Tunisia & 2 & 0 \\
\hline Turkey & 2 & 0 \\
\hline Ukraine & 2 & 5 \\
\hline Brazil & 1 & 1 \\
\hline Estonia & 1 & 0 \\
\hline Malaysia & 1 & 1 \\
\hline Spain & 1 & 2 \\
\hline Switzerland & 1 & 0 \\
\hline Taiwan & 1 & 2 \\
\hline Thailand & 1 & 1 \\
\hline Vietnam & 1 & 2 \\
\hline
\end{tabular}

the 'Institute for occupational and maritime medicine, Germany' is on the top followed by 'Statutory accident insurance institution for seafaring, Hamburg', and 'University of applied sciences, Berlin'. Surprisingly, the top three institutes are from Germany.
The work related to the mining of stress among seafarers has been funded by different agencies and universities. The list of funding agencies and the number of works supported during the last two decades have been shown in Figure 6 . The maximum amount of work in the concerned area has been supported by the University of Tasmania.

\section{HIGHLY CITED RESEARCHERS}

Citation is one of the significant research performance metrics. The list of top 20 cited researchers along with their total number of publication in the concerned area is presented in Table 5. It is found that M. Oldenburg is the top-cited researchers in this area. However, if the articles per citation are considered then X. Baur is on the top.

Likewise, the citation report of the articles explored using the search strategy (mentioned in section "Search strategy") has also been extracted. Some of the highly-cited key articles are mentioned in Table 6 [15-29].

The cumulative country-wise citations related to the theme under consideration are also presented (Table 7). It is found that the highest number of citations has been recorded for Germany followed by the United Kingdom and Canada. The countries where the cumulative citations are below ten have not been considered in this analysis.

\section{PSYCHOLOGICAL DISORDERS AND SEAFARERS}

The existing studies recognized that the prolonged or high intensity of the stress may trigger different human psychological disorders. Like stress, other human psychological disorders among seafarers need also to be mined (Table 8). No doubt, research has been carried out to mine and manage different human psychological disorders. The number of articles published for the psychological disorder in general and particularly in context to the seafarers has been extracted using a similar search strategy. The results witnessed a high number of publications in context to a different human psychological disorder in general. However, very few articles related to the mining of human psychological disorder particularly for seafarer has been identified. A minor change can be observed by altering the search strategy. However, the facts will remain same, i.e. as compared to the stress, more effort (research work) is required to mine the state of other human psychological disorders among the seafarer.

\section{CONCLUDING REMARKS AND FUTURE DIRECTIONS}

Here, an exhaustive bibliometric trend of international scientific articles for worldwide stress among seafarer has been examined. In the last two decades, stress among seafarer had observed a positive publishing trend. The publishing gap of distinct countries from 2001 to 2020 has 


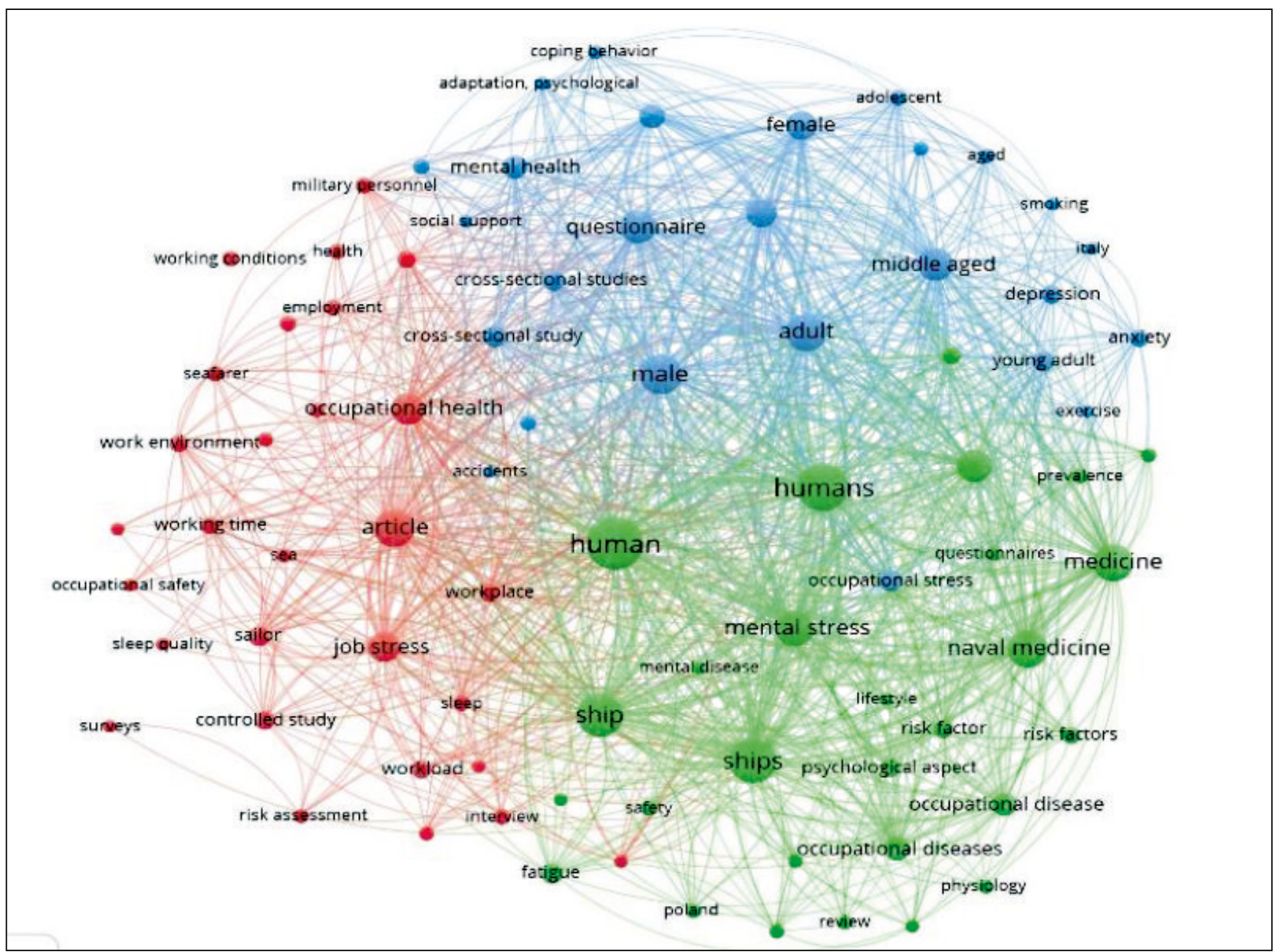

Figure 4. Keyword distribution

been highlighted. The study directed that Germany is the publishing leader in writing stress among seafarer based articles. The United Kingdom and Italy followed the trend of Germany. However, more effort is required from other developed countries like the United States, Canada, Australia, India, Thailand, Singapore etc. Concerning the article types, three different types of publications viz. journal articles (111, 81.6\%), conference proceedings (17, 12.5\%), and book chapters $(8,5.8 \%)$ have been considered. Based on sources, a high number of publications have been reported for journal articles, whereas editorial and notes are on the lower side. The $40 \%$ of the total articles have been contributed by Germany, United Kingdom and Italy only. Despite English, the articles have been published in five other languages viz. German, Italian, Croatian, French, and Chinese. The contribution of the articles published under subscription-based (67\%) model is significantly higher than open-access (37\%) articles. Additionally, as compared to stress a significant publishing gap has been observed for other human psychological disorders (bulimia, anorexia nervosa, obsessive-compulsive disorder, schizophrenia, generalised anxiety disorder, Cyclothymia, mood, conduct, personality) among the seafarer. The number of journals specific to psychological disorders among seafarer or mariners is very low. More specific journals related to this theme need to be added. Different scientific societies related to the distinct domains are available. However, a dedicated research society for this area needs also to be made. More funding projects need to be released for mining and management of distinct psychiatric disorders among mariners.

\section{CONFLICT OF INTEREST AND ETHICAL-APPROVAL}

The authors declare that they have no competing interests.

No ethical approval is required for this study. 
Table 4. Bifurcation publishing details

\begin{tabular}{|c|c|}
\hline Journal & Number of articles \\
\hline International Maritime Health & 29 \\
\hline International Archives of Occupational and Environmental Health & 6 \\
\hline Marine Policy & 4 \\
\hline Safety Science & 4 \\
\hline International Journal of Environmental Research and Public Health & 3 \\
\hline International Journal of Mechanical Engineering and Technology & 3 \\
\hline Journal of Occupational Medicine and Toxicology & 3 \\
\hline Maritime Policy and Management & 3 \\
\hline PLOS One & 3 \\
\hline Work & 3 \\
\hline Safety and Health at Work & 2 \\
\hline AIDS Education and Prevention & 1 \\
\hline Acta Biomedica & 1 \\
\hline Advanced Engineering Informatics & 1 \\
\hline African Journal of Marine Science & 1 \\
\hline Archives Des Maladies Professionnelles Et De L Environnement & 1 \\
\hline Archives of Environmental and Occupational Health & 1 \\
\hline Arhiv Za Higijenu Rada I Toksikologiju & 1 \\
\hline Asia Life Sciences & 1 \\
\hline Chronobiology International & 1 \\
\hline Entrepreneurship and Sustainability Issues & 1 \\
\hline Frontiers in Psychology & 1 \\
\hline Gazzetta Medica Italiana Archivio Per Le Scienze Mediche & 1 \\
\hline IEEE Transactions on Electrical and Electronic Engineering & 1 \\
\hline International Journal of Occupational Medicine and Environmental Health & 1 \\
\hline International Journal of Public Health & 1 \\
\hline Journal of Loss Prevention in The Process Industries & 1 \\
\hline Journal of Occupational Health and Safety Australia and New Zealand & 1 \\
\hline Journal of Pacific Rim Psychology & 1 \\
\hline Kindheit Und Entwicklung & 1 \\
\hline Marine Structures & 1 \\
\hline Maritime Studies & 1 \\
\hline Medicina Kaunas Lithuania & 1 \\
\hline Nase More & 1 \\
\hline Occupational Medicine & 1 \\
\hline Psychiatria Danubina & 1 \\
\hline Ricerca Folklorica & 1 \\
\hline Sociology of Health And IIIness & 1 \\
\hline Transportation Research Part-A Policy and Practice & 1 \\
\hline WMU Journal Of Maritime Affairs & 1 \\
\hline Zentralblatt Fur Arbeitsmedizin Arbeitsschutz Und Ergonomie & 1 \\
\hline Chinese Journal of Industrial Hygiene and Occupational Diseases & 1 \\
\hline
\end{tabular}




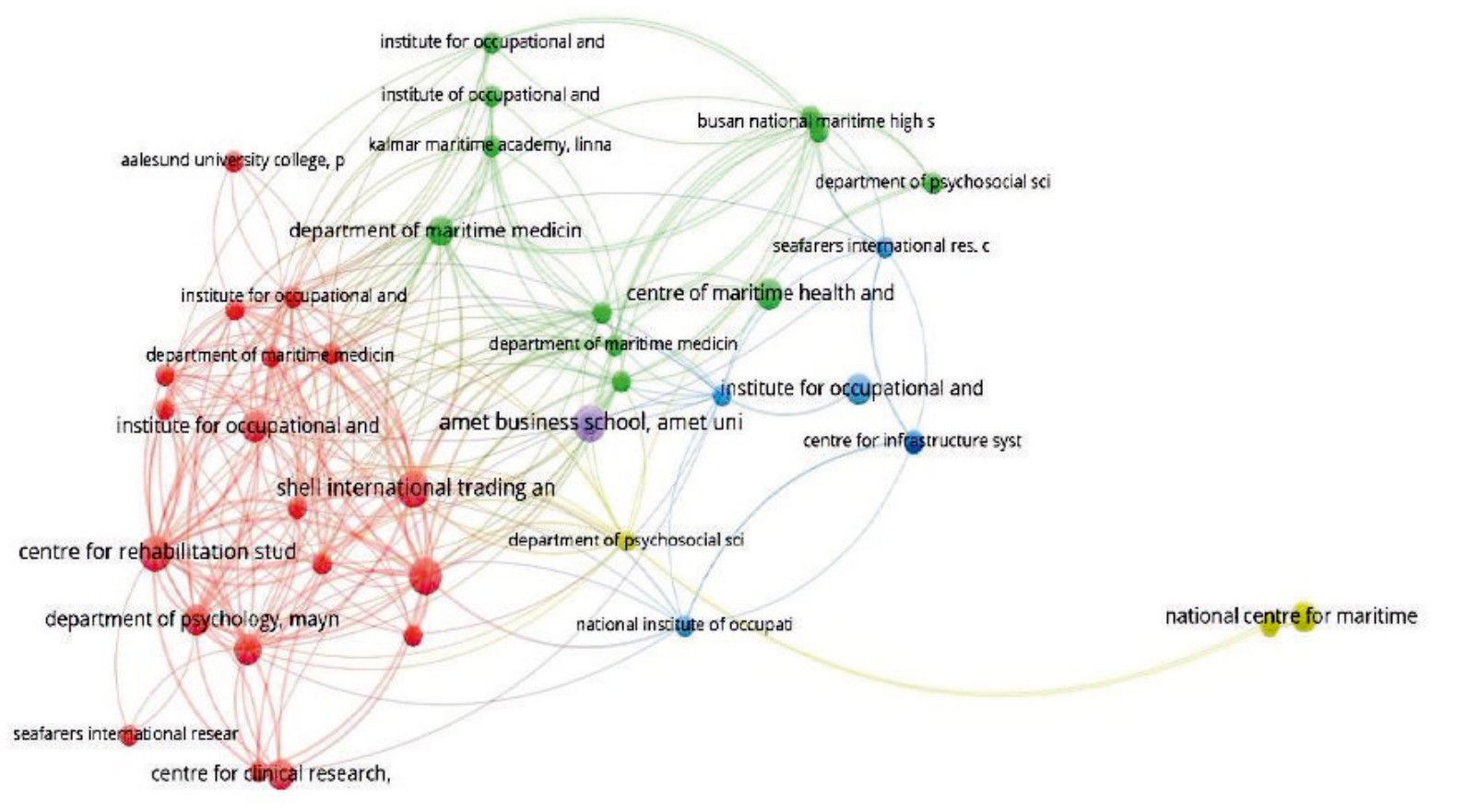

Figure 5. Citations (organisation)

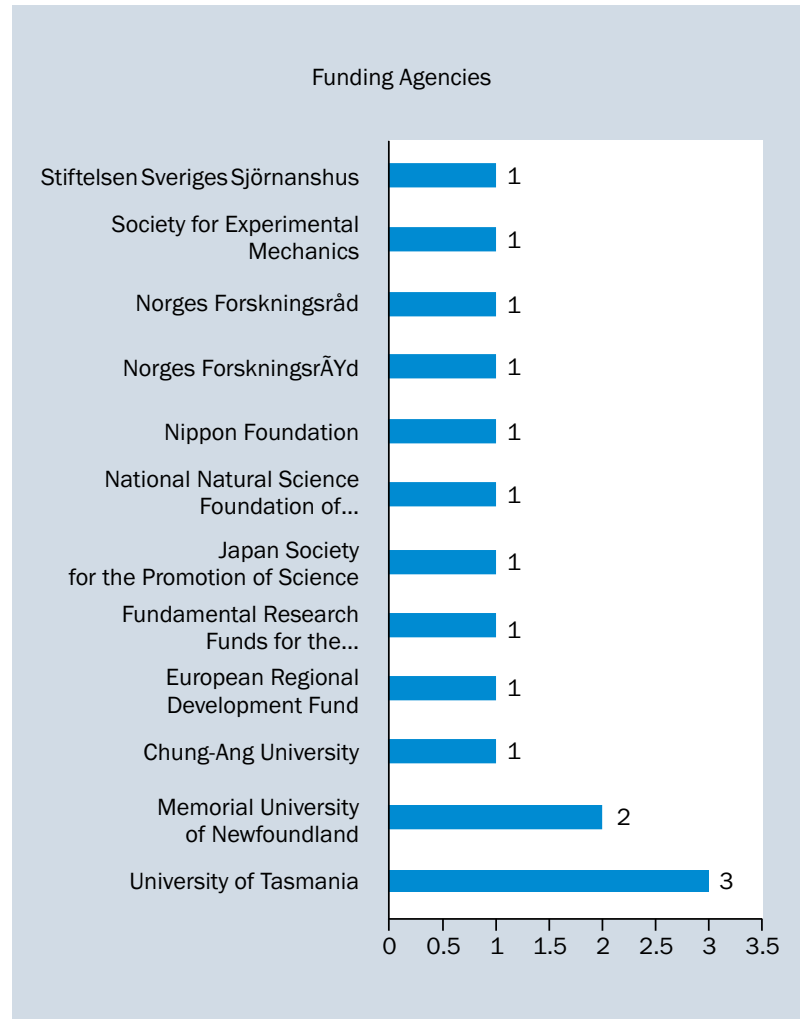

Figure 6. Funding agencies/universities
Table 5. Author's citation report

\begin{tabular}{lll}
\hline Author & Documents & Citations \\
\hline Oldenburg M. & 23 & 289 \\
Baur X. & 5 & 188 \\
Jensen H.-J. & 16 & 165 \\
Amenta F. & 8 & 87 \\
Fasanaro A.M. & 5 & 80 \\
Abbassi R. & 3 & 69 \\
Garaniya V. & 4 & 69 \\
Islam R. & 4 & 69 \\
Khan F. & 4 & 69 \\
Eid J. & 4 & 64 \\
Hystad S.W. & 3 & 44 \\
Maclachlan M. & 6 & 34 \\
Leppin A. & 3 & 31 \\
Mcveigh J. & 5 & 30 \\
Cox H. & 3 & 21 \\
Fraser A. & 3 & 21 \\
Stilz R. & 3 & 21 \\
Jezewska M. & 6 & 20 \\
Sibilio F. & 3 & 19 \\
Slišković A. & 3 & 19 \\
\end{tabular}


Table 6. Highly cited article

\begin{tabular}{lllll}
\hline Authors & Year & Cited by & Document type & Access type \\
\hline Oldenburg M. et al. [15] & 2010 & 81 & Review & Open access \\
Oldenburg M. et al. [16] & 2009 & 74 & Article & Subscription-based \\
Vickers D., Walsh V. [17] & 2005 & 69 & Article & Subscription-based \\
Carotenuto A. et al. [18] & 2012 & 58 & Review & Subscription-based \\
Thomas M. et al. [19] & 2003 & 58 & Article & Subscription-based \\
Watermeyer K.E. et al. [20] & 2008 & 37 & Article & Subscription-based \\
Oldenburg M. et al. [21] & 2013 & 34 & Review & Subscription-based \\
Islam R. et al. [22] & 2018 & 29 & Article & Open access \\
Hystad S.W., Eid J. [23] & 2016 & 27 & Article & Open access \\
Islam R. et al. [24] & 2017 & 23 & Article & Subscription-based \\
Oldenburg M. et al. [25] & 2008 & 23 & Article & Subscription-based \\
Haka M. et al. [26] & 2011 & 22 & Article & Subscription-based \\
Muraia K. et al. [27] & 2009 & 21 & Article & Subscription-based \\
Nielsen M.B. et al. [28] & 2013 & 20 & Article & Subscription-based \\
Bal E. et al. [29] & 2015 & 19 & Article & Subscription-based
\end{tabular}

Table 7. Countrywide citation

\begin{tabular}{|c|c|c|c|}
\hline Country & Documents & Citations & Total link strength \\
\hline Germany & 24 & 282 & 118 \\
\hline United Kingdom & 18 & 146 & 77 \\
\hline Canada & 6 & 139 & 11 \\
\hline Norway & 9 & 100 & 56 \\
\hline Australia & 6 & 72 & 13 \\
\hline South Africa & 5 & 64 & 54 \\
\hline Denmark & 9 & 46 & 32 \\
\hline Italy & 11 & 37 & 31 \\
\hline Ireland & 6 & 34 & 60 \\
\hline China & 8 & 30 & 35 \\
\hline South Korea & 5 & 28 & 10 \\
\hline Croatia & 6 & 26 & 28 \\
\hline Japan & 3 & 23 & 0 \\
\hline Sweden & 3 & 23 & 7 \\
\hline Poland & 7 & 31 & 7 \\
\hline Turkey & 2 & 20 & 0 \\
\hline United States & 6 & 18 & 7 \\
\hline India & 5 & 16 & 2 \\
\hline Thailand & 1 & 16 & 0 \\
\hline Singapore & 2 & 14 & 4 \\
\hline Czech republic & 3 & 13 & 40 \\
\hline Estonia & 1 & 11 & 0 \\
\hline Taiwan & 1 & 11 & 6 \\
\hline
\end{tabular}


Table 8. Publication analysis

\begin{tabular}{lll}
\hline Psychological disorders & No. of publication & \\
\cline { 2 - 3 } & General & Seafarer \\
\hline Bulimia & 17726 & $\mathrm{Nil}$ \\
Anorexia nervosa & 24497 & $\mathrm{Nil}$ \\
Obsessive-compulsive disorder & 32047 & $\mathrm{Nil}$ \\
Schizophrenia & 200662 & 01 \\
Generalised anxiety disorder & 14859 & $\mathrm{Nil}$ \\
Anxiety & 405383 & 31 \\
Depression & 738,227 & 35 \\
Mood disorder & 53900 & $\mathrm{Nil}$ \\
Personality disorder & 64510 & 01 \\
Conduct disorder & 11324 & $\mathrm{Nil}$
\end{tabular}

\section{REFERENCES}

1. Yu D, He X. A bibliometric study for DEA applied to energy efficiency: Trends and future challenges. Applied Energy. 2020; 268: 115048, doi: 10.1016/j.apenergy.2020.115048.

2. Kaur $P$, Sharma M. A survey on using nature inspired computing for fatal disease diagnosis. Int J Info System Modeling Design. 2017; 8(2): 70-91, doi: 10.4018/ijismd.2017040105.

3. Ghorbani R, Ghousi R. Predictive data mining approaches in medical diagnosis: A review of some diseases prediction. Int J Data Network Sci. 2019: 47-70, doi: 10.5267/j.ijdns.2019.1.003.

4. Kaur P, Sharma M. Diagnosis of human psychological disorders using supervised learning and nature-inspired computing techniques: a meta-analysis. J Med Syst. 2019; 43(7): 204, doi: 10.1007/ s10916-019-1341-2, indexed in Pubmed: 31139933.

5. Kelen G, Sauer LM. Trend analysis of disaster health articles in peer-reviewed publications pre- and post-9/11. Am J Disaster Med. 2008; 3(6): 369-376, indexed in Pubmed: 19202890.

6. Chuang KY, Chuang YC, Ho M, et al. Bibliometric analysis of public health research in Africa: The overall trend and regional comparisons. South Afr J Sci. 2011; 107(5/6), doi: 10.4102/ sajs.v107i5/6.309.

7. Poltronieri E. Open access publishing trend analysis: statistics beyond the perception. Info Res. 2016; 21(2).

8. Rahman M, Haque TL, Fukui T. Research articles published in clinical radiology journals: trend of contribution from different countries. Acad Radiol. 2005; 12(7): 825-829, doi: 10.1016/j. acra.2005.03.061, indexed in Pubmed: 16039536.

9. Lukic T, Blesic I, Basarin B, et al. Predatory and fake scientific journals/publishers: A global outbreak with rising trend: A review. Geographica Pannonica. 2014; 18(3): 69-81, doi: 10.5937/ geopan1403069l.

10. Takahashi K, Hoshuyama T, Ikegami K, et al. A bibliometric study of the trend in articles related to epidemiology published in occupational health journals. Occup Environ Med. 1996; 53(7): 433-438, doi: 10.1136/oem.53.7.433, indexed in Pubmed: 8704865.

11. Wisdom JP, Cavaleri MA, Onwuegbuzie AJ, et al. Methodological reporting in qualitative, quantitative, and mixed methods health services research articles. Health Serv Res. 2012; 47(2): 721-745, doi: 10.1111/j.1475-6773.2011.01344.x, indexed in Pubmed: 22092040.
12. Lee DH. A study on trend of the research papers published in the Journal of the Ergonomics Society of Korea. J Ergon Soc Korea. 2010; 29(4): 701-707, doi: 10.5143/jesk.2010.29.4.701.

13. Sharma M, Kaur P. A comprehensive analysis of nature-inspired meta-heuristic techniques for feature selection problem. Arch Computational Methods Engineering. 2020: 1-25, doi: 10.1007/ s11831-020-09412-6.

14. Gautam R, Sharma M. Prevalence and diagnosis of neurological disorders using different deep learning techniques: a meta-analysis. J Med Syst. 2020; 44(2): 49, doi: 10.1007/s10916-019-1519-7, indexed in Pubmed: 31902041.

15. Oldenburg M, Baur X, Schlaich C. Occupational risks and challenges of seafaring. J Occup Health. 2010; 52(5): 249-256, doi: 10.1539/ joh.k10004, indexed in Pubmed: 20661002.

16. Oldenburg M, Jensen HJ, Latza U, et al. Seafaring stressors aboard merchant and passenger ships. Int J Public Health. 2009; 54(2): 96-105, doi: 10.1007/s00038-009-7067-z, indexed in Pubmed: 19288290.

17. Vickers D, Vince W. Young men and the sea: Yankee seafarers in the age of sail. Yale University Press, Yale 2005.

18. Carotenuto A, Molino I, Fasanaro AM, et al. Psychological stress in seafarers: a review. Int Marit Health. 2012; 63(4): 188-194, indexed in Pubmed: 24595974.

19. Thomas M, Sampson H, Zhao M. Finding a balance: companies, seafarers and family life. Maritime Policy Management. 2010; 30(1): 59-76, doi: 10.1080/0308883032000051630.

20. Watermeyer KE, Shannon LJ, Griffiths CL. Changes in the trophic structure of the southern Benguela before and after the onset of industrial fishing. Afr J Marine Sci. 2008; 30(2): 351-382, doi: 10.2989/ajms.2008.30.2.11.561.

21. Oldenburg M, Hogan B, Jensen HJ. Systematic review of maritime field studies about stress and strain in seafaring. Int Arch Occup Environ Health. 2013; 86(1): 1-15, doi: 10.1007/s00420-0120801-5, indexed in Pubmed: 22915144.

22. Islam R, Khan F, Abbassi R, et al. Human error probability assessment during maintenance activities of marine systems. Saf Health Work. 2018; 9(1): 42-52, doi: 10.1016/j.shaw.2017.06.008, indexed in Pubmed: 30363076.

23. Hystad SW, Eid J. Sleep and fatigue among seafarers: the role of environmental stressors, duration at sea and psychological 
capital. Saf Health Work. 2016; 7(4): 363-371, doi: 10.1016/j. shaw.2016.05.006, indexed in Pubmed: 27924241.

24. Islam R, Abbassi R, Garaniya V, et al. Development of a human reliability assessment technique for the maintenance procedures of marine and offshore operations. J Loss Prevention i Process Industries. 2017; 50: 416-428, doi: 10.1016/j.jp.2017.10.015.

25. Oldenburg M, Jensen $\mathrm{HJ}$, Latza U, et al. Coronary risks among seafarers aboard German-flagged ships. Int Arch Occup Environ Health. 2008; 81(6): 735-741, doi: 10.1007/s00420-007-0261-5, indexed in Pubmed: 17909838.

26. Haka M, Borch DF, Jensen C, et al. Should I stay or should I go? Motivational profiles of Danish seafaring officers and non-offi- cers. Int Marit Health. 2011; 62(1): 20-30, indexed in Pubmed: 21534222.

27. Murai K, Wakida Si, Miyado T, et al. Basic study of a ship navigator's stress using salivary amylase activity. IEEJ Transactions Electrical Electronic Engineering. 2009; 4(5): 680-682, doi: 10.1002/tee.20462.

28. Nielsen MB, Bergheim K, Eid J. Relationships between work environment factors and workers' well-being in the maritime industry. Int Marit Health. 2013; 64(2): 80-88, indexed in Pubmed: 23788224.

29. Bal E, Arslan O, Tavacioglu L. Prioritization of the causal factors of fatigue in seafarers and measurement of fatigue with the application of the Lactate Test. Safety Science. 2015; 72: 46-54, doi: 10.1016/j.ssci.2014.08.003. 